\title{
Mística: experiência, tecitura e leitura
}

The mystique: experience and reading

Texto aprovado em

03.02.2021

Aprovado em

07.03.2021

V. 11 - N. 23 - 2021

*Université Sorbonne

Nouvelle - Paris

Fundação Educacional de Além Paraíba.

Contato:

sg.francisco@gmail.com

**Doutor em Letras pela

Pontifícia Universidade

Católica do Rio de Janeiro (PUC-Rio) em

2019. Mestre em Letras pela Universidade do Estado do Rio de Janeiro (UERJ) em 2014.Contato: sg.francisco@gmail.com

\section{*Francisco de Souza Gonçalves}

\section{* José Carlos de Lima Neto}

\section{Resumo}

O místico ou o indivíduo religioso, ao vivenciar a união com a divindade, tem a experiência "interior" de inteireza e completude. O leitor, ao ter contato com a poesia, por exemplo, além de voltar sua atenção para o sentido, pode-se sentir atraído pelo o ritmo, pela cadência do texto, pelas as evocações que ela suscita. Em um determinado momento, de forma surpreendente, este leitor pode vivenciar um tipo de contentamento espiritual, uma sensação de completude que não passa pela racionalidade. Falamos de uma conjugação de experiência mística/ religiosa e experiência estética, ambas provocadoras de abalos e subtração do indivíduo de seu cotidiano, num engendramento contínuo de sensações variadas. $\mathrm{O}$ escopo da presente pesquisa, ainda em curso, é variado, contém textos medievais, como o Boosco Deleitoso e obras contemporâneas.

Palavras-chave: mística, literatura, leitor.

\section{Abstract}

The mystic or the religious persoun, when 446 
experiencing the union with the divinity, has an "interior" experience of wholeness and completeness. The reader, when having contact with poetry, for example, in addition to turning his attention to the meaning, can be attracted by the rhythm, by the cadence of the text, by the evocations it evokes. At a certain moment, surprisingly, this reader can experience a type of spiritual content, a sense of completeness that does not pass through rationality. We speak of a combination of mystical / religious experience and aesthetic experience, both of which cause shaking and subtraction of the individual from his daily life, in a continuous engendering of varied sensations. The scope of this research, which is still ongoing, is varied, contains medieval texts, such as Boosco Deleitoso and contemporary works.

Keywords: mystique, literature, reader.

\section{O mistério}

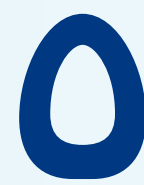

mistério pode ser considerado um ponto em comum entre literatura e religião. Não entendemos o termo como algo relacionado ao sobrenatural, ligado à ideia de milagroso, divino ou fora da realidade humana. Em nosso entender, mistério é aquilo que é de difícil compreensão, que foge aos domínios da razão; por sermos incapaz de enquadrar determinado acontecimento em uma lógica racional, talvez o caminho mais interessante seja o de envolver-se com o mistério ao invés de querer explicá-lo.

Queremos dizer com isso que literatura e religião, ao contrário de oferecerem somente elementos para serem interpretados, concedem ao indivíduo a possibilidade de interação com aquilo que é suscitado por ambas, ou seja, a leitura de um texto literário e busca intensa pela vivência da religião são capazes de produzir na pessoa envolvida com estes universos momentos de intensidade devido à dimensão de proximidade realmente física dispostas por elas. O mistério ao qual nos referimos é o caráter individual dessa relação entre a pessoa e o texto literário ou a pessoa e a vivência da religião, como também a impossibilidade de dar um sentido ao fenômeno acontecido a partir dessa relação, já que ao fazê-lo, a tendência é o desaparecimento ou desvanecimento da 
ocorrência. Portanto, a nosso ver, há um ponto em comum entre experiência estética e experiência religiosa (ou mística), que denominamos de produção de presença. Num primeiro momento deste trabalho, delimitaremos teoricamente o que é produção de presença. Em seguida, relacionaremos a experiência estética, a partir dos conceitos de produção de presença, à experiência mística, tendo por base um 'romance místico' medieval, chamado Boosco Deleitoso. Por último, abordaremos uma crônica de Cecília Meireles a fim de descobrir na leitura proposta um caminho que pode nos levar a uma verdadeira experiência estética. Ambas as experiências, como veremos no decorrer deste trabalho, apresentam-nos como lampejo o Ser, que na leitura de um texto literário pode ser um momento intenso e breve de desvelamento e descobertas, e na vivência religiosa pode ser Deus.

\section{A presença}

As pesquisas relacionadas ao campo literário e ao teológico de uma maneira geral encontram na linguagem e nos discursos produzidos em suas esferas o ponto de partida para a produção de conhecimento. Um crítico ou teórico literário pode buscar os elementos estruturais que compõem um determinado grupo de narrativas, por exemplo, a fim de 'clarificar' um percurso objetivo para a observação dos textos; ou em outro caso, o teórico pode elaborar através do texto literário um caminho que 'revele' o funcionamento de uma coletividade, demonstrando como a cultura se realiza através de certas identidades culturais. A teologia, pelo menos em âmbito cristão, é entendida como "um saber racional cujo objeto é dado pela revelação, transmitida e interpretada na Igreja sob a autoridade do magistério, e recebida pela fé"1. A referida revelação está inserida nos textos sagrados e o papel do teólogo é justamente fazer um trabalho especulativo, trazendo para o nível racional a experiência

1. CONGREGAÇÃO PARA A DOUTRINA DA FÉ. A vocação eclesial do teólogo (24/05/1990). http://www.vatican.va/roman curia/congregations/cfaith/documents/rc con cfaith doc 19900524 theologian-vocation po.html Acesso em 13/08/2018. 
da revelação de Deus. É importante reparar que por trabalharem com a linguagem e o discurso, a teologia e a teoria literária encontram nas mais variadas formas interpretativas uma maneira de atribuir sentido àquilo que lhes é apresentado. Notadamente há a primazia da busca pelo significado nessas duas áreas.

No entanto, os estudos de literatura e a teologia podem apelar, não sem algum risco de serem classificadas como 'anti-intelectuais', para uma abordagem em que se privilegie a busca da vitalidade dos textos e discursos propostos por ambas as áreas. Isto significa dizer que tais aproximações de forma alguma querem ser racionais, que buscam 'a verdade' intrínseca ao discurso literário ou bíblico; ao contrário, tal abeiramento com o textual pode proporcionar ao indivíduo uma proximidade no espaço com aquilo que é proposto nas linhas escritas, ou seja, é possível realmente haver um contato físico da pessoa com aquilo o texto seja ele literário ou bíblico/religioso evoca. Desta forma, fica evidente que contrapomos a racionalidade buscada nos referidos discursos à fisicalidade que o texto proporciona. Esse fenômeno de aproximação palpável é denominado de efeitos de presença, termo criado por Gumbrecht, professor de teoria literária em Stanford.

É inegável que a cultura ocidental é predominantemente voltada para o significado, resultando disso o constante desenvolvimento de técnicas interpretativas. Não sem motivos que a hermenêutica e a metafísica² estão nas bases de várias pesquisas no âmbito das Ciências Humanas; no entanto, esta afluência de significados para os objetos estudados, ao que parece, salvo raras exceções, não tem contribuído com nada de realmente novo. Os efeitos de presença podem ser considerados como uma possibilidade de oposição a esse marasmo intelectual, justamente porque propõe não uma análise racional do objeto, mas sugere que nos acerquemos dele a fim de que essa aproximação proporcione uma afe-

2. A metafísica, de maneira geral, surge na filosofia ocidental a fim de se ocupar com os significados subjacente às coisas, ou seja, com àquilo que está além do físico. 
tação do nosso estado de espírito ${ }^{3}$, ou em outras palavras, com o nosso estado emocional.

Presença, a princípio, não se coaduna com linguagem ${ }^{4}$, pois esta normalmente se refere à interpretação, via pela qual o objeto observado é compreendido de forma limitada ${ }^{5}$, enquanto aquela alega que nossa associação com o objeto não se dá somente por vias de atribuição de sentido, até porque a linguagem é incapaz de se referir ao objeto plenamente. Desta forma, utilizamos a palavra presença em sentido original do termo latino 'prae-esse', ou seja, à nossa frente, com isso queremos dizer que os objetos (todo e qualquer artefato cultural) estão à nossa frente, são tangíveis. Presença, portanto, é uma relação em que se verifica "o impacto dos objetos 'presentes' sobre corpos humanos"6.

Para formar a tese dos efeitos de presença, Gumbrecht vai alicerçar sua base na noção de Ser em Heidegger; o referido filósofo desloca o poder de verdade dos discursos da filosofia metafísica, que tem seu ponto de apoio na razão, para a dimensão das coisas, área a qual pertence o Ser. Em Ser e Tempo, Heidegger se afasta da ideia cartesiana de que sujeito e objeto estão separados no mundo; chega a esta conclusão por meio da análise do ser-no-mundo (Dasein), o homem e o mundo que o

3. Os estados de espírito se relacionam a uma disposição emocional que o indivíduo pode exteriorizar numa determinada ocasião; por exemplo: na leitura de uma poesia a pessoa pode sentir desperta em si algum tipo de afeição que antes da apreciação não existia. Tal sensação é de teor passageiro e de difícil explicação.

4. Gumbrecht afirma que a linguagem normalmente é utilizada para vias interpretativas. No entanto, há casos em que a linguagem se despe de seu caráter comunicativo e hermenêutico e passa a propiciar a cultura de presença, como é o caso da linguagem falada, que segundo o autor, afeta não somente os sentidos auditivos, mas todo o nosso corpo (GUMBRECHT, 2012, p. 66); como exemplo, cita a poesia declamada, que, mesmo sem o conhecimento da linguagem usada, pode suscitar no indivíduo uma experiência agradável, devido ao ritmo que possui efeito até mesmo inebriante em alguns casos. $\mathrm{O}$ autor ainda aproxima o ritmo da poesia às encantações mágicas associadas aos feitiços medievais, capazes de tornar presente objetos ausentes ou a ausência de objetos presentes (GUMBRECHT, 2012, p. 67). Dentre outros exemplos, o autor cita também a linguagem do misticismo, que, segundo ele, refere-se à sua própria incapacidade de representar a intensa presença do divino, mas que produz o efeito paradoxal de estimular imaginações que parecem tornar palpável essa mesma presença (GUMBRECHT, 2012, p. 69).

5. Cf. GUMBRECHT, 2012, p. 62

6. GUMBRECHT, 2010 , p. 13 
rodeia não estão em esferas diferentes; o ser-no-mundo de Heidegger permite a concepção dos efeitos de presença, pois reativa o corpo como esfera de conexão com o objeto. Heidegger pode ser considerado como o primeiro filósofo pós-metafísico que aprimora de forma sistemática conceitos que abordam a relação próxima do sujeito com o mundo para concorrer com a primazia do distanciamento científico entre estas duas instâncias ${ }^{7}$.

A produção de presença se alia à ideia de substancialidade do Ser justamente pela superação da abordagem interpretativa e metafísica. Sem fazer guerra à cultura de sentido, até porque o ser humano traz em sua condição o desejo de entender e buscar o sentido para interpretar o mundo que o cerca, a ideia de presença intenciona reanimar em nós uma maneira de nos relacionarmos de forma corporal com a matéria ou o objeto, seja ele artístico ou cultural.

\section{A experiência estética e experiência mística}

Entendemos por experiência estética as sensações que nascem da presença corporal do indivíduo com a materialidade do objeto; como já afirmado anteriormente, não há distanciamento entre estas duas realidades, pois a possibilidade desse tipo de experiência resulta justamente da relação substancial entre ambas.

Em nosso entender, os efeitos de presença que nascem da nossa relação corporal com o objeto artístico são os mesmos que podem surgir da nossa relação com Deus ou qualquer outro ser divino. Experiência estética e experiência mística manifestam a nossa relação corporal com o objeto cultural; uma relação muito próxima de um indivíduo com Deus, a ponto de senti-lo presente, ou a relação deste mesmo indivíduo com ambientes suscitados no romance, a ponto de ele sentir presente este mesmo ambiente no momento em que lê, mudando, consequentemente,

7. Cf. CASTRO, Susana de. Resenha do livro Produção de presença. Revista Descrições. Ano 3, n. 1, 2011. p. 108. 
o seu estado de espírito por causa das evocações do texto, são exemplos que manifestam que a experiência estética e mística são muito próximas. A pergunta que fica é a seguinte: como ocorre a experiência estética/mística em âmbito literário e religioso? Como já falado anteriormente, os efeitos de presença nascem do nosso contato físico com o objeto. Em âmbito literário, um bom exemplo é o poema. Tal gênero podem apresentar certos aspectos físicos, como o ritmo, por exemplo; dependendo do texto poético, somos embalados pelo ritmo e pelo tempo - a cadência - que realmente produzem respostas físicas no leitor ou ouvinte. A poesia, em sua essência, é oral e performática; temos a intuição de que ela se realiza plenamente quando é declamada, respeitando a entonação e o ritmo; talvez por isso outro teórico da literatura, Zumthor (2000, p. 18), dizia que a base da literatura é teatral, devido sua essência performática, que se plenifica e se torna viva na voz de quem a declama. Essa reação física do indivíduo nascida do aspecto físico do poema de forma alguma pode passar pelo crivo interpretativo, pois o indivíduo não consegue dobrar os sentimentos e sensações vivenciados, forjando-os pela razão. Em âmbito teológico e religioso, a linguagem mística é a que oportuniza a experiência. O próprio Gumbrecht (2010, p. 82) vai dizer que "o prazer da presença é a fórmula mística por excelência". A própria revelação, que está nas bases do estudo teológico, como vimos acima, nasce justamente de uma aproximação mística do indivíduo com Deus. A linguagem mística estimula a imaginação, meio pelo qual se torna palpável a presença do divino, ainda que não se perceba realmente o objeto.

A experiência estética e a experiência mística nascem de verdadeiros exercícios práticos em que se destacam a educação dos sentidos e a disposição para contemplação, que em nível religioso é a busca de atenção no divino, e em estâncias literárias é a busca de uma concentração tendo em vista o encantamento, a apreciação por aquilo que é lido. A poesia requer atitude de atenção, de disponibilidade do leitor, comportamento muito semelhante ao do místico, que para alcançar o êxtase não se baseia num movimento especulativo, centrado na racionalidade; ao 
contrário, a experiência mística se torna viável pela prática constante de exercícios espirituais (mantras, orações, jejuns, contemplação).

Por fim, a experiência estética e a experiência mística, por serem resultados de sensações e afetos, tendem a uma realidade que muitos teóricos da mística e teólogos já vinham antecipando em seus estudos: o caráter efêmero da experiência. Não é possível consolidarmos planos teóricos que elucidem o tema da experiência estética e mística, pois não há significação fixa para isto: cada indivíduo vive particularmente a experiência; o que nos cabe na literatura, em relação à experiência estética, é "descobrir princípios ativos em artefatos e entregar-se a eles de modo afetivo e cultural - render-se a eles e apontar na direção deles"8; e em relação à experiência mística, Bingemer (2013, p. 300-301) afirma que o seu conteúdo está presente no testemunho dos místicos, ou seja, é lendo o testemunho místico que se lê a revelação de Deus. Portanto, neste trabalho, a partir de agora, queremos nos debruçar sobre o efeito de presença no Boosco Deleitoso, obra medieval de cunho místico, e na obra de Cecília Meireles.

\section{A experiência mística em O Boosco Deleitoso}

O Boosco Deleitoso é uma obra da literatura portuguesa de cunho místico. Há poucas informações sobre ele; sabe-se que foi impresso precisamente no dia 24 de maio do ano de 1515 por Hermão de Campos (BOOSCO DELEITOSO, 1950, p. 344), a pedido da rainha Eleonor, esposa do rei D. João II de Portugal (BOOSCO DELEITOSO, 1950, p. 1). Contudo, vários estudiosos da literatura portuguesa e filólogos são unânimes em afirmar que a sua redação pode ser situável entre fins do século XIV e início do XV (PINTO-CORREA, 1999, p. 17).

Há, ainda, a questão da autoria, caso bastante discutido quando se trata de algumas produções artísticas ou intelectuais na Idade Média. Neste caso, é preciso considerar que originalidade na Idade Média con-

8. GUMBRECHT, 2014, p. 30 
sistia em repetir modelos já preestabelecidos e consagrados; tal reprodução na contemporaneidade condenaria a obra por plágio. Além de não conhecermos o autor da referida obra, este transcreve boa parte do livro De vita solitária, de Francesco Petrarca, compondo mais da metade do texto português com traduções livres do referido texto humanista. Os quinze capítulos iniciais, como também do capítulo cento e dezoito até o cento e cinquenta e três, é de autoria portuguesa; o entremeio disto, portanto, é escrito a partir da obra italiana citada, numa tradução livre.

A crítica mais tradicional não via com bons olhos a falta de originalidade do Boosco Deleitoso. Entretanto, os estudiosos de literatura da contemporaneidade têm procurado dissipar esta ideia. De acordo com eles, o autor do Boosco Deleitoso conseguiu manipular o texto do De vita Solitária de forma esplêndida: o tema do livro italiano está centrado no elogio e na busca da vida solitária para desfrutar do ócio literário; o autor português se apropriou de forma inteligente deste elogio à vida solitária, só que redirecionando o seu fim, ou seja, a vida apartada do mundo tendo em consideração o desenvolvimento da vida espiritual (COELHO DOS SANTOS, 1999, p. 25). Sem dúvidas, a parte portuguesa é a mais interessante do Boosco Deleitoso e é aquela em que se observa a tonalidade mística da obra.

O termo mística vem do verbo grego myo que significa 'calar-se', 'fechar os olhos' com o intuito de entrar em contato com o mistério. Para muitos, a mística é entendida como uma fuga da realidade e da vida e por isso é vista com certa suspeita ${ }^{9}$. No entanto, ela resgata algo que parece estar esquecido nos meios intelectuais: a possibilidade de nos relacionarmos espacialmente com o objeto cultural a fim de sermos impactados por ele, ao invés de somente explorá-lo de modo racional, atribuindo-lhe mais e mais significações que acabam por nos colocar progressivamente distante dele. Não é por acaso que tanto se celebra o distanciamento científico como forma de se alcançar o sentido que há no objeto.

9. Cf. BINGEMER, 2013, p. 16 
Os místicos, ao invés de explicar o objeto Deus, buscam estabelecer relações de cunho afetivo, que nascem a partir do silencio e da contemplação, culminando num contato de tonalidades realmente físicas, que são possíveis pelo caminho da imaginação ${ }^{10}$. Aproveitando o que já explicamos anteriormente, o místico se diferencia do teólogo na medida em que ele e Deus estão de igual para igual, ou seja, não há afastamento entre as duas partes; Deus, como objeto cultural, e o homem pertencem ao mesmo mundo das coisas e não são ontologicamente separados dele ${ }^{11}$; o teólogo especulativo, ao contrário, põe Deus como objeto de observação e, portanto, cria-se um distanciamento que impossibilita a 'desvelamento do Ser'12;

O Boosco Deleitoso é um romance místico que narra o percurso espiritual da Alma feito de encontros e desencontros com Deus. Todo esse caminho ascético é narrado por meio de uma linguagem erótica:

A minha alma entom ouvia a voz do Senhor Deus, seu esposo e seu amado, quando se nembrava dele; e entom havia grande desejo de o veer e entom o viia, quando se maravilhava da sua majestade e beijava-o polo grande amor que the havia e abraçava-o pela grande deleitaçom que enele havia. (BOOSCO DELEITOSO, 1950, p. 323)

A experiência mística acontece justamente porque o indivíduo se colocou em relação direta e papável com Deus. Os textos místicos nascem, em nosso entender, com o intuito de suscitar no leitor o mesmo tipo de experiência vivida e o recurso utilizado por eles é a imaginação, meio pelo qual tornam palpável a presença física do divino, apesar de não podermos afirmar ou negar por meios racionais que Deus realmente exista como objeto real.

10. A imaginação é capaz de produzir reações corporais iguais à presença real de um objeto; um conto de terror, por exemplo, pode fazer surgir no leitor o medo, como se o perigo textualmente criado fosse real.

11. Cf. GUMBRECHT, p. 64

12. O Ser substitui a ideia de verdade na metafísica, que sempre nasce por meio da racionalidade. O Ser foge a qualquer realidade objetivante: está na ordem do inefável. 
Como se nota no trecho acima, o místico utiliza imagens eróticas em sua linguagem a fim de trabalhar com a imaginação do leitor e, por isso a linguagem mística muito se aproxima da linguagem literária. A produção de presença em literatura em muitos casos está amplamente relacionada ao caráter imaginativo do texto e, de fato, a imaginação tem forte apelo em nossas sensações. O mesmo acontece com a linguagem mística que, ao invés de representar Deus, aponta para ele: a expressão mística pode ser entendida como forma de abertura para o mundo dos objetos e não como tentativa de abarcá-los significativamente. A linguagem erótica que atravessa toda essa parte mística do Boosco Deleitoso, ao que nos parece, é baseada na criação de imagens que de alguma forma potencializa o surgimento ou o acontecimento de outras experiências místicas nos leitores:

E entom a minha alma soo por soo com o Senhor, seu esposo mui amado; e ela estando soo, viia e oolhava ele soo per contempraçom, e tanto viia a minha alma o seu amado per contepraçom, ataa que pouco e pouco ia esquecendo-se per esguardamento de visom que ante nom soia ver, e maravilhando-se da fremosura do amado. E assi ardia mais e mais com amor e, em cabo, alguuas vezes se acendia, ataa que chegava aa verdadeira simpreza, toda reformada em verdadeira pureza e em fremosura de dentro; e entom aquela câmara e aquele taámo da morada de dentro da minha alma era apostado de toda parte com púrpura e com bisso alvo de limpeza e com jacinto. Ca em na minha limpeza e jacinto de prudência. $E$ depois que o taámo mais de dentro da minha alma era perfeiramente apostado e ordenado e o amado era dentro metido, crecia a fiúza aa minha alma e tomava grande atrevimento e com grande atrevimento e com grande desejo, que costrangia, nom se podia mais deteer, e lançava-se subitamente aos beijos do seu amado e, com os beiços apegados enele, aficava-Ihe beijos de devaçom, mui de dentro do coraçom (BOOSCO DELEITOSO, 1950, p. 323-324).

Fremoso e aposto és tu, meu amado; tira-me depós ti, e eu correrei em odor dos teus inguentos; porque, assi como deseja o cervo as fontes das águas, assi desejo a ti, meu Senhor Deus. (BOOSCO DELEITOSO, 1950, p. 339). 
Em ambos os trechos, o erotismo das imagens agencia de alguma forma nossos dispositivos de sensação, afinando-nos àquela atmosfera proposta; o leitor, inebriado com o conteúdo da narração e guiado pela trama do texto, alcança uma sensação interior, um estado de espírito que é difícil pôr em palavras. Em nível literário, chamamos tal evento de experiência estética; num nível religioso, denominamos de experiência mística. No entanto, importa saber que tal acontecimento só se realiza porque o indivíduo se envolveu de forma natural com o objeto a ponto de se harmonizar com ele.

\section{A crônica de Cecília Meireles}

Cecília Meireles é sem dúvida um dos maiores expoentes da literatura de língua portuguesa: "foi escritora atenta à riqueza do léxico e dos ritmos portugueses, tendo sido o poeta moderno que modulou com mais felicidade os metros breves"13. Respeitada pela sua produção poética, poucos conhecem sua produção cronística; como se observa em uma de suas coletâneas chamada $O$ que se diz e o que se entende, a escritora se demonstra interessada desde os pequenos eventos do cotidiano até pontos de discussão sobre ética e problemas que tangenciam os limites extremos do ser humano ${ }^{14}$. Numa escrita envolvente, a autora parece encaminhar seu leitor a se comprazer com a beleza dos fatos, com construções cênicas e rítmicas que fazem aflorar a sensibilidade de modo muito natural.

Em algumas crônicas da referida coletânea, temos a sensação de estarmos diante de um texto em que se privilegia novamente a linguagem mística, ou seja, uma linguagem que procura colocar o leitor diante do fato, não para ser discutido ou racionalizado, mas para ser vivido; o encontro entre essas duas instâncias, o leitor e o objeto narrado, permite o evento da experiência estética.

13. BOSI, 2006, p. 461

14. Cf. DAMASCENO, Darcy. Cotidiano, nostalgia e transcendência. In. MEIRELES, Cecília. O que se diz e o que se entende. Rio de Janeiro: Nova Fronteira, 1980. 
Na crônica Ano muito bom, a escritora narra uma viagem de avião que fez para a Índia. Obviamente viajavam um grupo bastante eclético de pessoas, de vários lugares do mundo. Era a noite do dia 31 de dezembro. Praticamente ninguém se conhecia e, aquilo que todos os passageiros tinham em comum se restringia à admiração do Mediterrâneo, das pirâmides, dos desertos, enfim, imagens notadas das janelinhas do avião. No início da crônica, Cecília discorre sobre o individualismo: cada passageiro com sua vida, com seus projetos, com seus sonhos, suas ocupações. A tonalidade e o ritmo da narrativa começam a mudar quando ela comenta que aquela noite, para quem tinha deixado o Ocidente, era especial: era o ano novo. Num crescente, ela passa a recordar tradições de antigas festas pagãs de herança romana, mescladas, posteriormente, ao cristianismo que até hoje fazemos, com algumas alterações; antes do êxtase final, a aeromoça, vestida de sári azul é descrita como um anjo, juntamente com o comandante, vem participar da festa. Então ocorre o momento grandioso: aqueles passageiros que não se conheciam, de repente passam a agir como se fossem irmãos; cada um em sua língua desejava o feliz ano novo, no entanto, não havia falta de entendimento, pois todos falavam o idioma da esperança e da ternura, como bem narra Cecília Meireles. Em seguida, prolongando esse êxtase, a escritora fala dos contrários que se uniram num fervoroso abraço: o ano velho e o ano novo; o céu e a terra; o Oriente e o Ocidente. Para terminar, Cecília, pensativa, exprime que seria muito bom se conseguíssemos começar todos os dias do ano desse mesmo jeito.

Observamos que na crônica acima a escritora, de modo sutil, vai elaborando um ambiente narrativo que nos insere de forma participativa naquele voo para a Índia; sentimos a emoção de estar presente em um momento tão grandioso e perceber que todas as diferenças, pelo menos naqueles primeiros minutos do ano novo, estavam superadas, dando lugar à fraternidade e a concórdia.

A crônica, apesar de ser um gênero sucinto, demonstra que consegue de forma muito intensa captar em instantes fugidios a substância 
para produzir a experiência estética no leitor. Novamente, a imaginação que o texto provoca é aquilo que, a nosso ver, torna capaz tal experiência e nos confere a sensação de vivermos aquele momento de unidade. Tal como a narração mística, a crônica consegue estimular em nós a presença do objeto narrado: a unidade e fraternidade entre as pessoas, que antes da leitura poderia estar ausente como estado de espírito no leitor, tornou-se presente de forma sensível por meio da imaginação criada no momento da apreciação do texto.

\section{Considerações finais}

Há vários pontos de contato entre a experiência estética e a experiência mística e neste trabalho destacamos os efeitos de presença, que se referem diretamente a uma relação espacial do indivíduo com os objetos: o místico, após vivenciar por meio de práticas de concentração a presença de Deus, busca pelo seu testemunho trazê-lo para frente do indivíduo, a fim de que possa também vivenciar a sensação de totalidade que tal encontro produz; o recurso utilizado pelo místico para testemunhar tal encontro é a imaginação, que torna presente aquilo que está ausente. Gumbrecht vai dizer que "o prazer da presença é a fórmula mística por excelência"; na literatura, como foi possível observar na crônica de Cecília Meireles, os efeitos de presença também podem ser provocados através da narração que cria um ambiente envolvente por meio das imagens que suscita. Em ambos os casos, temos a sensação de tocar os objetos e de sermos tocados por eles. Em linhas gerais, o sagrado da religião e a harmonia da arte convergem para um mesmo lugar: para a promoção de momentos de intensidade na vida humana, ocasiões que de fato nos retiram do fluxo contínuo da vida e que nos impactam de tal forma, favorecendo-nos a sensação de inteireza e liberdade. 


\section{Referências}

BINGEMER, Maria Clara Lucchetti. O mistério e o mundo: paixão por Deus em tempos de descrença. Rio de Janeiro: Rocco, 2013.

BOOSCO DELEITOSO (séc. XVI). Compilado por Augusto Magne. Rio de Janeiro: Instituto Nacional do Livro, 1950.

CASTRO, Susana de. Resenha do livro Produção de presença. Revista Descrições. Ano 3, n. 1, 2011. p. 108

GUMBRECHT, Hans Ulrich. Produção de presença: o que o sentido não consegue transmitir. Tradução: Ana Isabel Soares. Rio de Janeiro: Contraponto: Ed. PUC-Rio, 2010.

GUMBRECHT, Hans Ulrich. Presença na linguagem ou presença contra a linguagem? In. GUMBRECHT, H. U. Graciosidade e estagnação: ensaios escolhidos. Introdução e organização Luciana Villas Bôas; Tradução Luciana Villas Bôas e Markus Hediger. Rio de Janeiro: Contraponto; Ed. PUC-Rio, 2012.

GUMBRECHT, Hans Ulrich. Atmosfera, ambiência, Stimmung: sobre um potencial oculto da literatura. Tradução: Ana Isabel soares. Rio de Janeiro: Contraponto: Editora PUC-Rio, 2014.

MEIRELES, Cecília. O que se diz e o que se entende: crônicas. Rio de Janeiro: Nova Fronteira, 1980. 